https://helda.helsinki.fi

\title{
Antibacterial efficiency of Finnish spice essential oils against pathogenic and spoilage bacteria
}

\author{
Nevas, $M$. \\ International Association for Food Protection \\ 2004
}

Journal of food protection. 2004. 67: 199-202

http://hdl.handle.net/1975/771

Downloaded from Helda, University of Helsinki institutional repository.

This is an electronic reprint of the original article.

This reprint may differ from the original in pagination and typographic detail.

Please cite the original version. 


\title{
Research Note
}

\section{Antibacterial Efficiency of Finnish Spice Essential Oils against Pathogenic and Spoilage Bacteria}

\author{
MARI NEVAS, ${ }^{1 *}$ ANNA-RIITTA KORHONEN, ${ }^{2}$ MIIA LINDSTRÖM, ${ }^{1}$ PEKKA TURKKI, ${ }^{2}$ AND HANNU KORKEALA ${ }^{1}$
}

${ }^{1}$ Department of Food and Environmental Hygiene, Faculty of Veterinary Medicine, 00014 University of Helsinki, Finland; and ${ }^{2} Y T 1-R e s e a r c h$ Centre, P.O. Box 181, 50101 Mikkeli, Finland

MS 03-126: Received 19 March 2003/Accepted 26 July 2003

\begin{abstract}
The antibacterial properties of 13 essential oils, derived from spices grown in Finland, were examined with an agar diffusion method against 12 bacterial strains. The organisms tested included both spoilage and pathogenic bacteria. The grampositive bacteria appeared to be more sensitive than the gram-negative organisms, Clostridium botulinum and Clostridium perfringens being the most sensitive. Oregano, savory, and thyme showed the broadest antibacterial activity by distinctly inhibiting the growth of all the organisms tested. By gas chromatography-mass spectrometry analysis, differences were noted in the composition of oregano and thyme oils in comparison to previous reports.
\end{abstract}

Spices are aromatic plant products that are used in flavoring foods and beverages. They are known to provide a wide range of compounds with antimicrobial activity, which is mainly associated with the fraction of volatile essential oils. Essential oils could serve as potential antibacterial agents, thus prolonging the shelf life of certain food products. They might also provide alternatives to food additives, such as nitrite, that potentially have undesirable effects on human health (20).

The antimicrobial and antifungal efficiency of different plant essential oils has been studied previously $(3,4,6,7$, 11-13). However, it has been reported that the antimicrobial properties can vary within the same plant species because the chemical composition and relative proportions of the individual constituents in the essential oils of the plants are influenced by genotype, growth stage, drying, climate, and geographical location $(2,15,19)$. The antimicrobial activity of oregano, savory, and thyme was first reported during the $1950 \mathrm{~s}$ (11). It was later established that the inhibitory effect of oregano, savory, and thyme is likely due to their high content of thymol and carvacrol, which are among the most efficient herbal antibacterial agents known $(7,18)$. It has also been noted that the production of phenolic compounds increases under warm, dry conditions (13).

In the present study, the efficacy of certain spice essential oils in preventing growth of several bacterial strains was evaluated in vitro. All the oils studied are derived from herbs grown in outdoor gardens in Finland, located between latitudes 60 and $70^{\circ} \mathrm{N}$ in Northern Europe. It is thus possible to assess the influence of this northern climate with its relatively short growing period and moderate rainfall on the antibacterial activities of these oils. The thermal growth

* Author for correspondence. Tel: +358-9-191 49744; Fax: +358-9-191 49718; E-mail: mari.nevas@helsinki.fi. period in the production area of the herbs lasts approximately 140 to 175 days, but the persistence of snow in spring can shorten the period further by 2 to 3 weeks. On the other hand, the time period between sunrise and sunset is extended, varying from 15 to $19 \mathrm{~h}$ during June, July, and August in southern Finland. There are 73 so-called polar days per year in northern Finland, during which the sun does not set below the horizon at all. The mean summer temperatures were approximately 14 to $16^{\circ} \mathrm{C}$ in the area where these spices were grown.

\section{MATERIALS AND METHODS}

Bacterial strains. Twelve pathogenic and food spoilage bacteria used as test organisms are listed in Table 1.

Herbal oils. Essential oils, produced by steam distillation, were purchased from three producers: cumin, dill, Japanese mint A, peppermint, and sweet cicely oils from producer 1 ; angelica A, lovage, and southernwood oils from producer 2; and angelica B, Japanese mint B, oregano, savory, and thyme oils from producer 3. All the oils were obtained from plants harvested in 1999 and were $100 \%$ of herbal origin. At the time of the study, the oils were 3 months old, being stored in refrigerator.

Antibacterial analysis. Antibacterial analysis was performed with the agar diffusion method (6). A test culture of each bacterial strain was prepared in Iso-sensitest broth (Oxoid Ltd., Hampshire, UK) to a concentration of $1 \times 10^{6}$ organisms per ml. The inoculated agar plates were produced by mixing $1 \mathrm{ml}$ of test culture in $25 \mathrm{ml}$ of molten Iso-sensitest agar, $\mathrm{pH} 7.4 \pm 0.2$ (Oxoid). After the agar plates were solidified, 4-mm-diameter wells were punched into the agar, six per petri dish. A volume of $10 \mu \mathrm{l}$ of oil was inoculated into each well. To allow the oils to diffuse into agar plates, they were kept at $20^{\circ} \mathrm{C}$ for $30 \mathrm{~min}$, before transfer to the incubator. The plates were incubated at $25^{\circ} \mathrm{C}$ for $48 \mathrm{~h}$. A parallel sample was examined for each combination of bacterium and 
TABLE 1. Bacterial strains used in the study

\begin{tabular}{ll}
\hline \multicolumn{1}{c}{ Microorganism } & \multicolumn{1}{c}{ Strain } \\
\hline Bacillus cereus & ATCC 10702 \\
Brochothrix thermosphacta & ATCC 11509 \\
Clostridium botulinum (Type B) & SL-1 B (proteolytic) ${ }^{a}$ \\
C. botulinum (Type E) & 211E (nonproteolytic) ${ }^{a}$ \\
C. perfringens & ATCC 3626 \\
Enterobacter aerogenes & ATCC 13048 \\
Escherichia coli & ATCC 25922 \\
Lactobacillus sakei & ATCC 15521 \\
Listeria monocytogenes & NCTC 7973 \\
Salmonella Typhimurium & ATCC 14028 \\
Staphylococcus aureus & ATCC 14458 \\
Yersinia enterocolitica & 118E/2 a \\
\hline
\end{tabular}

${ }^{a}$ Strains were provided by the Department of Food and Environmental Hygiene, Faculty of Veterinary Medicine, University of Helsinki.

oil. After the incubation, the inhibition zones were measured and duplicate results averaged.

GC-MS. The chemical composition of the three antimicrobially most potent spice essential oils was determined with gas chromatography-mass spectrometry (GC-MS) analysis (1). For this analysis, the oils were dissolved in ethyl acetate to the following concentrations: oregano, $1.004 \mathrm{mg} / \mathrm{ml}$; savory, $1.076 \mathrm{mg}$ / $\mathrm{ml}$; and thyme, $1.424 \mathrm{mg} / \mathrm{ml}$. The volume of the sample injected was $1 \mu \mathrm{l}$. A Hewlett-Packard 6890 combination gas chromatograph-mass spectrometer (Waldbronn, Germany) was used as follows: capillary column HP- 5 ( $30 \mathrm{~m}$ by $0.25 \mathrm{~mm}$; phase thickness, $0.25 \mu \mathrm{m})$; temperature program $40^{\circ} \mathrm{C}(2 \mathrm{~min})$, raised to $250^{\circ} \mathrm{C}(5$ min) at a rate of $10^{\circ} \mathrm{C} / \mathrm{min}$; and carrier gas helium at a flow rate of $0.9 \mathrm{ml} / \mathrm{min}$. The components were recognized by the retention times of the chromatogram peaks and by their mass spectra. The identities of the main component peaks were confirmed by comparison of their retention times with those of authentic samples.

\section{RESULTS AND DISCUSSION}

A total of 12 of the 13 spice essential oils studied possessed antibacterial properties (Table 2). In general, the gram-positive bacteria showed the most distinctive sensitivity to the oils, Listeria monocytogenes being the least sensitive of the gram-positive organisms studied. The differences in sensitivity between the gram-positive and gramnegative bacteria are demonstrated in Figure 1. The grampositive Clostridium botulinum types B and E, together with Clostridium perfringens, were the most sensitive, and the gram-negative Enterobacter aerogenes, Salmonella Typhimurium, and Escherichia coli the organisms most resistant to the essential oils studied. Four oils (angelica A, dill, lovage, and sweet cicely) inhibited only the growth of gram-positive organisms, and angelica B was the only oil showing no antimicrobial activity.

Oregano, savory, and thyme showed broad antimicrobial activity, inhibiting all 12 bacterial strains studied, including the gram-negative organisms. The main component detected in oregano and savory was carvacrol, whereas the major constituent of thyme appeared to be thymol (Table 3 ). Thymol, carvacrol, or both and their precursors, $p$-cymene and $\gamma$-terpinene, dominated in all three herbs.

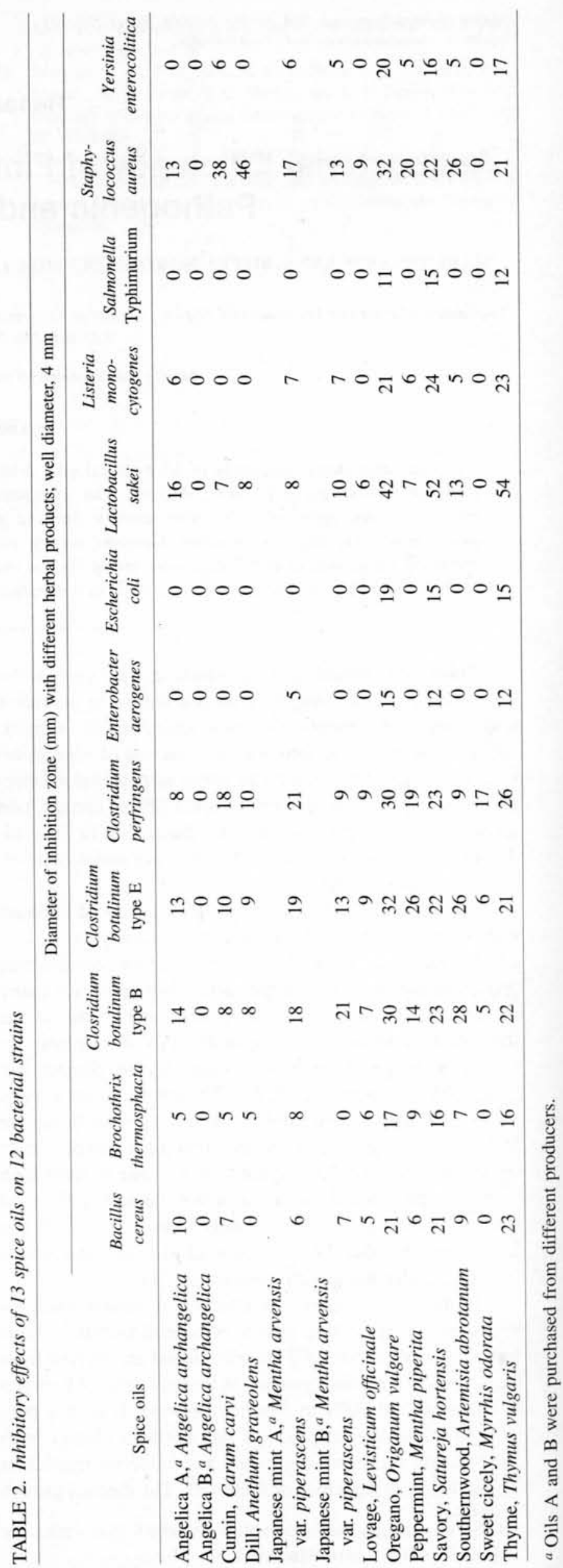




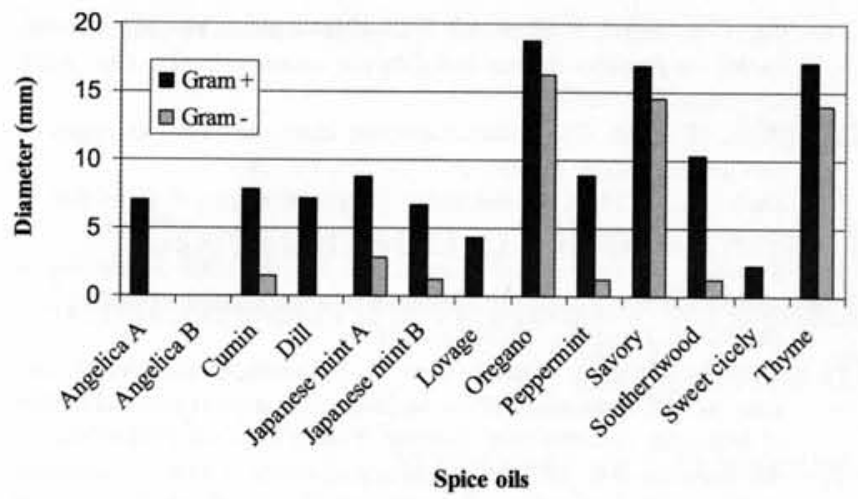

FIGURE 1. Average inhibition zones of 12 spice oils against 13 bacteria according to their gram-staining abilities.

In this study, it is shown that oils of several spices grown in Finland have various antibacterial activities against both gram-negative and gram-positive bacteria, the gram-positive being more sensitive. It was previously shown that gram-positive bacteria are more sensitive than the gram-negative $(5,17)$, whereas others reported no such differences occurring between these two groups $(6,7)$.

These high susceptibilities, especially of $C$. botulinum, to different oils could indicate that it is feasible to decrease the content of nitrite in meat products by combining certain oils with nitrite, while still maintaining an inhibitory environment for the growth of $C$. botulinum. However, it is to be noticed that in the study of Ismaiel and Pierson (9), it was shown that even though the antimicrobial activities of origanum oils against $C$. botulinum were increased synergistically with sodium nitrite in TYG broth, the inhibitory effect was reduced in the meat product.

The geographic location and the climate could have influenced the proportions of phenolic components. The proportions of thymol, carvacrol, $p$-cymene, and $\gamma$-terpinene make up $74 \%$ of oregano oil of Finnish origin, although including less than $1 \%$ thymol. In oregano oil of Greek origin, the four compounds make up $92 \%$ of the oil, with $13.7 \%$ thymol (10). Carvacrol was reported to be one of the major constituents in thyme (2), but in the present survey, no carvacrol was detected. However, the composition of savory oil showed only slight differences in the proportions of thymol, oregano, $p$-cymene, and $\gamma$-terpinene compared with those reported in savory collected from Portugal (8). There were also differences between antimicrobial activities in oils derived from different purchasers, indicating the presence of factors other than climate or geographic location that could influence the oil quality.

Antimicrobial activity can be enhanced with a combination of two antimicrobially effective spices or by combining oil constituents with other antimicrobials. $(14,17)$. Even though certain spice extracts inhibit some microorganisms efficiently in growth media in vitro, their antibacterial efficiency is diminished when they are added to more complex materials, such as food products (16). This is because of the fat, protein, water, and salt content, which can affect antimicrobial activity. On the other hand, the characteristic odor and taste of some compounds restricts the use of essential oils in concentrations needed to inhibit mi-
TABLE 3. Components of oregano, savory, and thyme essential oils (expressed as \% wt/wt composition)

\begin{tabular}{|c|c|c|c|}
\hline \multirow[b]{2}{*}{ Oil component } & \multicolumn{3}{|c|}{ Composition (\% wt/wt) } \\
\hline & Oregano & Savory & Thyme \\
\hline Tricyclene & $\mathrm{ND}^{a}$ & ND & 0.06 \\
\hline$\alpha$-Thujene & 3.18 & 2.27 & 1.91 \\
\hline$\alpha$-Pinene & 2.19 & 2.12 & 1.89 \\
\hline Camphene & 0.51 & 0.18 & 1.08 \\
\hline$\beta$-Pinene & 0.36 & 1.03 & 0.46 \\
\hline$\beta$-Myrcene & 3.69 & 2.46 & 2.91 \\
\hline$\alpha$-Phellandrene & 0.59 & 0.59 & 0.64 \\
\hline 3-Carene & 0.3 & 0.15 & 0.33 \\
\hline$\alpha$-Terpinene & 3.16 & 6.75 & 4.83 \\
\hline p-Cymene & 10.98 & 10.12 & 20.68 \\
\hline$\beta$-Phellandrene & ND & 0.19 & ND \\
\hline$\gamma$-Terpinene & 10.75 & 34.73 & 18.68 \\
\hline Terpinolene & 0.3 & 0.23 & 0.47 \\
\hline Linalool & ND & ND & 2.40 \\
\hline Camphor & ND & ND & 0.28 \\
\hline Terpinen-4-ol & 0.58 & 0.42 & 0.99 \\
\hline Thymol methylether & 1.3 & ND & 0.37 \\
\hline Thymol & 0.71 & 0.19 & 32.86 \\
\hline Dihydrocarvone & 0.13 & 0.12 & ND \\
\hline Carvacrol & 51.83 & 32.36 & ND \\
\hline Carvacrol acetate & ND & ND & 0.36 \\
\hline Copaene & ND & ND & 0.13 \\
\hline$\beta$-Caryophyllene & 2.93 & ND & 3.55 \\
\hline Aromadendrene & 0.09 & ND & ND \\
\hline$\alpha$-Humulene & 0.37 & 0.07 & 0.14 \\
\hline$\gamma$-Cadinene & 0.23 & ND & 0.36 \\
\hline$\beta$-Bisabolene & ND & 1.27 & ND \\
\hline 8-Cadinene & 0.26 & ND & 0.40 \\
\hline $\begin{array}{l}\text { Total proportion of } \\
\text { components identified }\end{array}$ & 94.63 & 95.25 & 95.78 \\
\hline
\end{tabular}

${ }^{a} \mathrm{ND}$, component not detected.

crobial growth. Therefore, further studies are needed to estimate the potential for utilizing spice extracts as additives in extending the safety and shelf life of food products.

\section{REFERENCES}

1. Adams, R. P. 1995. Identification of essential oil components by gas chromatography/mass spectroscopy. Baylor University, Plant Biotechnology Center. Allured Publishing Corp., Carol Stream, Ill.

2. Arrebola, M. L., M. C. Navarro, J. Jiménez, and F. A. Ocána. 1994. Yield and composition of the essential oil of Thymus serpylloides subsp. serpylloides. Phytochemistry 1:67-72.

3. Aureli, P., A. Constantini, and S. Zolea. 1992. Antimicrobial activity of some plant essential oils against Listeria monocytogenes. J. Food Prot. 5:344-348.

4. Conner, D. E., and L. R. Beuchat. 1984. Effects of essential oils from plants on growth of food spoilage yeasts. J. Food Sci. 49:429434.

5. Dankert, J., TH. F. J. Tromp, H. De Vries, and H. J. Klasen. 1979. Antimicrobial activity of crude juices of Allium ascalonicum, Allium cepa and Allium sativum. Zbl. Bakt. Hyg., I. Abt. Orig. A 245:229239.

6. Deans, S. G, and G. Ritchie. 1987. Antibacterial properties of plant essential oils. Int. J. Food Microbiol. 5:165-180.

7. Deans, S. G., and K. P. Svoboda. 1989. Antibacterial activity of summer savory (Satureja hortensis L.) essential oil and its constituents. J. Hortic. Sci. 64:205-210. 
8. Esquivel, M. M., M. A. Ribeiro, and M. G. Bernardo-Gil. 1999. Supercritical extraction of savory oil: study of antioxidant and extract characterization. J. Supercrit. Fluids 14:29-138.

9. Ismaiel, A. A., and M. D. Pierson. 1990. Effect of sodium nitrite and origanum oil on growth and toxin production of Clostridium botulinum in TYG broth and ground pork. J. Food Prot. 11:958960.

10. Lagouri, V., G. Blekas, M. Tsimidou, S. Kokkini, and D. Boskou. 1993. Composition and antioxidant activity of essential oils from oregano plants grown wild in Greece. Z. Lebensm.-Unters.-Forsch. 197:20-23.

11. Maruzzella, J. C., and L. Liguori. 1958. The in vitro antifungal activity of essential oils. J. Am. Pharmacol. Assoc. 4:250-254.

12. Piccaglia, R., and M. Marotti. 1993. Characterization of several aromatic plants grown in northern Italy. Flavour Frag. J. 8:115-122.

13. Piccaglia, R., M. Marotti, E. Giovanelli, S. G. Deans, and E. Eaglesham. 1993. Antibacterial and antioxidant properties of Mediterranean aromatic plants. Ind. Crop Prod. 2:47-50.
14. Pol, I. E., and E. J. Smid. 1999. Combined action of nisin and carvacrol on Bacillus cereus and Listeria monocytogenes. Lett. Appl. Microbiol. 29:166-170.

15. Rhyu, H. 1979. Gas chromatographic characterization of sages of various geographic origins. J. Food Sci. 44:758.

16. Shelef, L. A. 1983. Antimicrobial effects of spices. J. Food Saf. 6: 29-44.

17. Shelef, L. A., O. A. Naglik, and D. W. Bogen. 1980. Sensitivity of some common food-borne bacteria to the spices sage, rosemary and allspice. J. Food Sci. 45:1042-1044.

18. Sivropoulou, A., E. Papanikolaou, C. Nikolaou, S. Kokkini, T. Laranas, and M. Arsenakis. 1996. Antimicrobial and cytotoxic activities of origanum essential oils. J. Agric. Food Chem. 44:1202-1205.

19. Venskutonis, P. R. 1996. Effect of drying on the volatile constituents of thyme (Thymus vulgaris L.) and sage (Salvia officinalis L.). Food Chem. 2:219-227.

20. Walker, R. 1990. Nitrates, nitrites and $N$-nitrosocompounds: a review of the occurrence in food and diet and the toxicological implications. Food Addit. Contam. 6:717-768. 